ISSN 0103-8478

\title{
Caracterização física, química e físico-química de physalis cultivada em casa de vegetação
}

\author{
Chemical, physical and physical-chemical characterization of physalis cultivated in greenhouse \\ Filipe Almendagna Rodrigues ${ }^{\mathrm{I}^{*}}{\text { Edwaldo dos Santos Penoni }{ }^{\mathrm{I}} \text { Joyce Dória Rodrigues Soares }}^{\mathrm{I}}$ \\ Renata Alves Lara Silva ${ }^{\mathrm{I}}$ Moacir Pasqual ${ }^{\mathrm{I}}$
}

\section{- NOTA -}

\section{RESUMO}

A physalis (Physalis peruviana L.) é uma frutifera, pertencente à família Solanaceae, muito difundida no mercado internacional, principalmente por seu sabor e suas características medicinais, tornando-a atrativa para o mercado e comercialização. Objetivou-se determinar e correlacionar as características biométricas apresentadas por frutos e sementes e caracterizar fisica, fisico-quimica e quimicamente of fruto de physalis, cultivado em casa de vegetação em Lavras-MG. Avaliaram-se nos frutos de physalis os caracteres diâmetros transversal e longitudinal do fruto, massa do fruto, massa do fruto com cálice, massa de sementes por fruto, massa de 100 sementes, massa de 1000 sementes e número de sementes por fruto, sendo que essas características foram avaliadas quando o cálice estava no estádio amarelo. Também foram avaliados a firmeza, coloração dos frutos, sólidos solúveis, acidez titulável, $\mathrm{pH}$, açúcares solúveis totais, pectina total e solúvel. O cultivo de physalis (P. peruviana L.) em casa de vegetação pode ser recomendado, pois essa condição possibilita a obtenção de frutos com características adequadas às normas de comercialização, tais como, conteúdo de sólidos solúveis de no mínimo $14^{\circ}$ Brix e ratio $\geq 6,0$.

Palavras-chave: Physalis peruviana L., sólidos solúveis, firmeza, fruticultura, Solanaceae.

\section{ABSTRACT}

The physalis (Physalis peruviana L.) is a fruit belonging to the Solanaceae family, widespread in the international market, mainly for its flavor and its medicinal characteristics, making it attractive to the market and marketing. This study aimed to determine and correlate the biometrics submitted by fruits and seeds and characterize physical, chemical and physicochemically physalis fruit grown in the greenhouse in Lavras-MG. Were evaluated in the fruits of physalis characters longitudinal and transverse diameters of the fruit, fruit weight, fruit mass with Chalice, seed mass per fruit, 100 seed weight, weight of 1000 seeds and number of seeds per fruit, and these characteristics were evaluated when the cup was in the yellow stage. We also evaluated the firmness, fruit color, soluble solids, titratable acidity, $\mathrm{pH}$, total soluble sugars, total and soluble pectin. Growing physalis (P. peruviana L.) in a greenhouse can be recommended because this condition allows obtaining appropriate features fruit with marketing standards, such as soluble solids content of at least $14^{\circ}$ Brix and ratio $\geq 6.0$.

Key words: Physalis peruviana L., soluble solids, firmness, fruticulture, Solanaceae.

A physalis (Physalis peruviana L.) é uma frutífera, pertencente à família Solanaceae, muito difundida no mercado internacional, principalmente por seu sabor e suas características medicinais, tornando-a atrativa para o mercado e comercialização. O seu consumo ainda é restrito, devido ao alto valor agregado, em decorrência da produção limitada, do manejo da colheita, da exigência em mão de obra, dos cuidados no transporte e do armazenamento. Os frutos apresentam sabor açucarado, bons conteúdos de vitamina A e C, ferro e fósforo, flavonoides, alcaloides e fitoesteroides (TOMASSINI et al., 2000), e as características físico-químicas relacionadas ao sabor, odor, textura e valor nutritivo constituem atributos de qualidade à comercialização e utilização da polpa na elaboração de produtos industrializados.

A physalis trata-se de uma excelente alternativa de renda para o pequeno e médio produtor rural brasileiro, sendo atualmente cultivada em solo. Porém, IANCKIEVICZ et al. (2013) relatam que o cultivo sucessivo em solo provoca a ocorrência de

\footnotetext{
IDepartamento de Agricultura, Universidade Federal de Lavras (UFLA), 37200-000, Lavras, MG, Brasil. E-mail: filipealmendagna@yahoo.com.br.

*Autor para correspondência. 
problemas fitossanitários, ambientais e nutricionais, inviabilizando a cultura em algumas regiões. Em contrapartida, RODRIGUES et al. (2013) afirmam que é possível produzir physalis em vaso, em condição de casa de vegetação.

Sendo assim, objetivou-se com este trabalho determinar e correlacionar as características biométricas de frutos e sementes e avaliar física, físico-química e quimicamente os frutos de physalis (P. peruviana L.) cultivados em casa de vegetação, em Lavras-MG.

Foram conduzidos dois experimentos: o primeiro no Laboratório de Cultura de Tecidos Vegetais, do Departamento de Agricultura da Universidade Federal de Lavras (UFLA), e o segundo no Laboratório de Pós-colheita de Frutas e Hortaliças, do Departamento de Ciência dos Alimentos (DCA) da UFLA, Lavras-MG.

A semeadura da physalis foi realizada em janeiro de 2011 em bandejas contendo substrato comercial Tropstrato $^{\circledR}$. Após 30 dias, quando as plantas apresentavam $15 \mathrm{~cm}$ de comprimento, procedeu-se ao transplantio para vasos de plástico preto com capacidade para $4 \mathrm{~L}$, contendo o mesmo substrato utilizado na fase de germinação. Adotou-se o sistema de condução do tipo espaldeira com três fios de arame galvanizado, sendo o primeiro fio situado a $0,5 \mathrm{~m}$ do solo, o segundo a $1,0 \mathrm{~m}$ e o terceiro a $1,5 \mathrm{~m}$. O espaçamento foi de $1,5 \mathrm{~m}$ entre plantas e $1,5 \mathrm{~m}$ na linha. A colheita dos frutos iniciou-se 100 dias após o transplantio das mudas da bandeja para os vasos. A irrigação foi feita diariamente e não foi realizada adubação.

Dois lotes de frutos de physalis foram colhidos no mês de julho de 2011, em plantas com cinco meses de idade, apresentando cálice no estádio amarelo. O primeiro lote foi levado ao Laboratório de Cultura de Tecidos Vegetais, onde se avaliaram diâmetro transversal e longitudinal do fruto $(\mathrm{mm})$ com auxílio de paquímetro digital e massa do fruto, massa do fruto com cálice, massa de sementes por fruto, massa de 100 sementes $(\mathrm{g})$ secas à sombra por 24 horas, por meio de balança analítica de precisão, e número de sementes por fruto.

Utilizou-se delineamento experimental inteiramente casualizado. Para análise de diâmetro longitudinal do fruto, diâmetro transversal do fruto, massa do fruto e massa do fruto com cálice, utilizaramse oito repetições contendo 10 frutos. Para número de sementes por fruto, utilizaram-se cinco repetições de 10 frutos e, para aferição da massa de sementes, coletaram-se aleatoriamente 100 sementes, sendo os dados obtidos por meio de balança analítica de precisão. Os dados foram avaliados estatisticamente através do teste $t$ de Student e de coeficientes de correlação de Pearson ( $5 \%$ de probabilidade).

$\mathrm{O}$ outro lote de frutos foi utilizado para o segundo experimento após seleção. Os frutos foram separados em oito repetições de cinco frutos cada e, em seguida, avaliaram-se: Firmeza, determinada individualmente no fruto inteiro na região equatorial, com auxílio de um penetrômetro Magness - Taylor com sonda de $5 / 6$ polegadas de diâmetro. A velocidade da carga celular foi de $20 \mathrm{~cm} \mathrm{~min}^{-1}$, sendo os resultados expressos em Newton $(\mathrm{N})$; Coloração, medida na casca do fruto com auxílio de um colorímetro Minolta CR 400, no modo CIE L*a*b, em que se calculou o ângulo Hue $\left(\mathrm{h}^{\mathrm{o}}\right)$; Sólidos solúveis $(\mathrm{SS})$, determinados por refratometria, utilizando-se o refratômetro digital e os resultados expressos em ${ }^{\circ}$ Brix; Acidez titulável (AT), expressa em porcentagem de ácido cítrico; Ratio, relação entre $\mathrm{SS}$ e $\mathrm{AT}$ e $\mathrm{pH}$, avaliado por potenciometria.

Além das características citadas acima, também se analisaram: açúcares solúveis totais (AST), segundo metodologia proposta por DISCHE (1962) e resultados expressos em g de glicose por $100 \mathrm{~g}$ de tecido, e pectina total (PT) e solúvel (PS), determinadas por espectrofotômetro, a $520 \mathrm{~nm}$, segundo BLUMENKRANTZ \& ASBOE-HANSEN (1973), sendo os resultados expressos em mg de ácido galacturônico por $100 \mathrm{~g}$ de polpa.

Os frutos de physalis apresentaram diâmetros médios transversal e longitudinal de $16,89 \mathrm{~mm}$ e $18,17 \mathrm{~mm}$, respectivamente. Quanto à massa do fruto, foi encontrado em média 2,843g por fruto, massa do fruto com cálice em média de $3,050 \mathrm{~g}$, massa de sementes por fruto igual a $0,124 \mathrm{~g}$. Já em relação à massa de sementes, foram calculados a média de 100 sementes e número médio de sementes por fruto, verificando-se, respectivamente, $0,095 \mathrm{~g}$ e 135 sementes.

Na tabela 1, são descritos os coeficientes de correlação entre as diferentes características estudadas. Observa-se correlação altamente positiva entre as variáveis massa de fruto e massa do fruto com cálice $(0,962)$, ou seja, quanto maior massa do fruto com o cálice, maior será a massa do fruto.

Correlacionando-se os diâmetros longitudinal e transversal com a massa do fruto, foram observadas correlações significativas e positivas de 0,915 e 0,896 , respectivamente, ou seja, os diâmetros longitudinal e transversal variaram de forma direta em relação à massa do fruto. Já as variáveis massa de sementes e número de sementes apresentam correlações negativas com as variáveis diâmetro transversal, diâmetro longitudinal, massa do fruto e massa do fruto com cálice, o que é particularmente interessante ao consumidor final, uma vez que, quanto 
Tabela 1 - Estimativas dos coeficientes de correlação de Pearson entre as diferentes características (diâmetro transversal; diâmetro longitudinal; massa do fruto; massa do fruto com cálice; massa de sementes e número de sementes) avaliadas em frutos de physalis.

\begin{tabular}{|c|c|c|c|c|c|c|}
\hline Variável & $\begin{array}{c}\text { Diâmetro } \\
\text { transversal } \\
(\mathrm{mm})\end{array}$ & $\begin{array}{l}\text { Diâmetro } \\
\text { longitudinal } \\
(\mathrm{mm})\end{array}$ & $\begin{array}{c}\text { Massa do } \\
\text { fruto }(\mathrm{g})\end{array}$ & $\begin{array}{l}\text { Massa do fruto } \\
\text { com cálice }(\mathrm{g})\end{array}$ & $\begin{array}{c}\text { Massa de } \\
\text { sementes }(g)\end{array}$ & $\begin{array}{l}\text { Número de } \\
\text { semente }\end{array}$ \\
\hline Diâmetro transversal & 1,000 & $0,837^{*}$ & $0,915^{*}$ & $0,939^{*}$ & $-0,096^{\mathrm{ns}}$ & $-0,193^{\mathrm{ns}}$ \\
\hline Diâmetro longitudinal & & 1,000 & $0,896^{*}$ & $0,892^{*}$ & $-0,197^{\mathrm{ns}}$ & $-0,208^{\text {ns }}$ \\
\hline Massa do fruto & & & 1,000 & $0,962^{*}$ & $-0,280^{\mathrm{ns}}$ & $-0,310^{*}$ \\
\hline Massa do fruto com cálice & & & & 1,000 & $-0,120^{\mathrm{ns}}$ & $-0,220^{\mathrm{ns}}$ \\
\hline Massa de sementes & & & & & 1,000 & $0,972^{*}$ \\
\hline Número de sementes & & & & & & 1,000 \\
\hline
\end{tabular}

${ }^{\mathrm{ns}}$ não significativo; ${ }^{*}$ significativo a $5 \%$, pelo teste $t$ de Student.

maior o fruto, em termos de tamanho e massa, menor será o número de sementes (Tabela 1 ).

Ainda na tabela 1 , verifica-se que as maiores correlações encontradas $(0,962$ e 0,972$)$ foram entre a massa do fruto e massa do fruto com cálice e massa de sementes e número de sementes. A massa correlacionase bem com o tamanho do fruto e constitui uma característica da variedade. Há correlação significativa $(0,972)$ entre massa de sementes e número de sementes. Dessa forma, pode-se inferir que, quanto maior a massa de sementes por fruto, maior será o número de sementes por fruto. Já massa do fruto e número de sementes apresentam correlações significativas e negativas, ou seja, essas variáveis se comportaram de forma inversa. Quanto maior o número de sementes, menor será a massa do fruto, ou seja, maior quantidade de sementes por fruto resulta em uma menor quantidade de polpa no fruto, o que se torna indesejável.

Com relação à coloração dos frutos, analisou-se o ângulo Hue $\left(\mathrm{h}^{\circ}\right)$, que expressa a localização da cor em um diagrama, em que o ângulo $0^{\circ}$ representa vermelho puro, $90^{\circ}$ representa o amarelo puro, $180^{\circ}$ o verde puro e $270^{\circ}$ o azul. No presente estudo, verificou-se que os frutos apresentaram média de Hue de 77,86 $\pm 0,34$, o que corresponde à faixa do amarelo. Segundo o ICONTEC (1999), para que frutos de physalis sejam comercializados, a sua coloração deve variar do alaranjado ao laranja intenso.

Já nas análises químicas de $\mathrm{pH}$, acidez titulável (AT) e sólidos solúveis (SS), foram encontrados, respectivamente, 3,46 $\pm 0,14$, $1,57 \pm 0,03 \%$ e $13,81 \pm 0,05^{\circ}$ Brix. Estes parâmetros são comumente utilizados como indicativo da qualidade do fruto, refletindo no estádio de maturação dele, sendo a sua concentração e composição componentes indispensáveis ao sabor do fruto (ARAÚJO et al., 2009). Segundo as normas da ICONTEC (1999), para a comercialização da physalis, a relação SS/AT (ratio) deve ser $\geq 6,0$, correspondendo ao índice de maturação mínimo permitido para comercialização. No entanto, esta variável deve estar associada a outras características de qualidade, como o conteúdo de sólidos solúveis, em que o valor mínimo deve ser de $14^{\circ}$ Brix (LIMA et al., 2009).

No presente trabalho, o ratio foi de $8,80 \pm 0,02$, ou seja, os frutos estão no ponto ideal para comercialização. Além disso, este parâmetro fornece uma indicação da qualidade/maturação do fruto. Desse modo, quando se obtém uma razão muito baixa, há indicação de que se trata de um fruto mais ácido do que desejável. Quando se observa um valor elevado, é um indicativo de que o fruto está em estado de maturação mais avançado. Tais condições influenciam diretamente o sabor dos frutos das solanáceas (LIMA et al., 2009).

Os frutos de physalis cultivados em casa de vegetação apresentaram $20,25 \pm 0,21 \mathrm{~N}$ para a variável firmeza. A firmeza está diretamente associada não só com a composição e estrutura das paredes celulares, como também com a manutenção de sua integridade. Segundo VELASQUEZ et al. (2007), a firmeza é o melhor indicador prático da maturação de uma fruta, como o caso da physalis, pois esta avaliação determina os níveis ótimos para consumo, transporte e manejo do produto.

Com relação às variáveis pectina total, pectina solúvel e açúcares solúveis totais foram encontrados no presente estudo, respectivamente, $279,119 \pm 0,137 \mathrm{mg}$ de ácido galacturônico $100 \mathrm{~g}^{-1}$, $124,835 \pm 0,092 \mathrm{mg}$ de ácido galacturônico $100 \mathrm{~g}^{-1} \mathrm{e}$ $12,107 \pm 0,241 \mathrm{~g}$ de glicose $100 \mathrm{~g}^{-1}$. Maiores índices de pectina total são importantes para a conservação da fruta em pós-colheita, visto que as pectinas influenciam na textura do fruto e também no custo de 
processamento industrial, devido à menor necessidade de adição de pectina comercial e redução do tempo de fabricação do doce em massa, a exemplo de geleia (CHITARRA \& CHITARRA, 2005).

O cultivo de physalis ( $\boldsymbol{P}$. peruviana L.) em casa de vegetação pode ser recomendado, pois essa condição possibilita a obtenção de frutos com características adequadas às normas de comercialização, tais como, conteúdo de sólidos solúveis de, no mínimo, $14^{\circ}$ Brix e ratio $\geq 6,0$.

\section{REFERÊNCIAS}

ARAÚJO, E.R. et al. Caracterização físico-química de frutos de biri-biri (Averrhoa bilimbi L.). Biotemas, v.22, n.4, p.225230, 2009.Disponível em: <https://periodicos.ufsc.br/index.php/ biotemas/article/view/2175-7925.2009v22n4p225>. Acesso em: 03 dez. 2013. doi:10.5007/2175-7925.2009v22n4p225.

BLUMENKRANTZ, N.; ASBOE-HANSEN, G.New method for quantitative determination of uronic acids. Analytical Biochemistry, v.54, n.2, p.484-489, 1973. Disponível em: <http:// www.sciencedirect.com/science/article/pii/0003269773903771>. Acesso em: 04 dez. 2013. doi: 10.1016/0003-2697(73)90377-1.

CHITARRA, M.I.F.; CHITARRA, A.B. Pós-colheita de frutos e hortaliças: fisiologia e manuseio. 2.ed. Lavras: UFLA, 2005. 785p.

DISCHE, Z. General color reactions. In: WHISTLER, R.L.; WOLFRAM, M.L. Carbohydrate chemistry. New York: Academic, 1962. p.477-512.
IANCKIEVICZ, A.et al. Produção e desenvolvimento da cultura de Physalis peruviana L. submetida a diferentes níveis de condutividade elétrica da solução nutritiva. Ciência Rural, v.43, n.3, p. 438-444, 2013.Disponível em: <http://dx.doi.org/10.1590/ S0103-84782013000300010>. Acesso em: 04 dez. 2013. doi: 10.1590/S0103-84782013000300010.

ICONTEC - INSTITUTO COLOMBIANO DE NORMAS TÉCNICAS. NTC 4580: frutas frescas, uchuva, especificaciones. Bogotá, 1999. 15p.

LIMA, C.S.M. et al. Características físico-químicas de Physalis em diferentes colorações do cálice e sistemas de condução. Revista Brasileira de Fruticultura, v.31, n.4, p.1060-1068, 2009.Disponível em: <http://dx.doi.org/10.1590/S0100-29452009000400020>. Acesso em: 19 mar. 2012. doi: 10.1590/S0100-29452009000400020.

RODRIGUES, F.A. et al. Caracterização fenológica e produtividade de Physalis peruviana cultivada em casa de vegetação. Bioscience Journal, v.29, n.6, p.1771-1777, 2013. Disponível em:<http://www.seer.ufu.br/index.php/biosciencejournal/article/ view/21859/13414>. Acesso em: 04 dez. 2013.

TOMASSINI, T.C.B. et al. Gênero Physalis: uma revisão sobre vitaesteróides. Química Nova, v.23, n.1, p.47-57, 2000. Disponível em: <http://dx.doi.org/10.1590/S0100-40422000000100011>. Acesso em: 19 mar. 2012. doi: 10.1590/S0100-40422000000100011.

VELASQUEZ, H.J.C. et al. Estudio preliminar de la resistencia mecánica a la fractura y fuerza de firmeza para fruta de uchuva (Physalis peruviana L.). Revista Facultad Nacional de Agronomía, v.60, n.1, p.3785-3796, 2007.Disponível em: <http:// www.scielo.org.co/pdf/rfnam/v60n1/a11v60n1.pdf >. Acesso em: 03 dez. 2013. 